\title{
Lower thermospheric nitric oxide concentrations derived from WINDII observations of the green nightglow continuum at $553.1 \mathrm{~nm}$
}

\author{
C. H. A. von Savigny ${ }^{1}$, I. C. McDade ${ }^{1,2}$, G. G. Shepherd ${ }^{1,2}$, Y. Rochon ${ }^{1}$ \\ ${ }^{1}$ Centre for Research in Earth and Space Science, York University, Toronto, Ontario M3J 1P3, Canada \\ E-mail: mcdade@windeh.yorku.ca \\ ${ }^{2}$ Department of Earth and Atmospheric Science, York University, Toronto,Ontario, M3J 1P3, Canada
}

Received: 25 November 1998 / Revised: 28 May 1999 / Accepted: 1 June 1999

\begin{abstract}
Vertical profiles of nitric oxide in the altitude range 90 to $105 \mathrm{~km}$ are derived from $553 \mathrm{~nm}$ nightglow continuum measurements made with the Wind Imaging Interferometer (WINDII) on the Upper Atmosphere Research Satellite (UARS). The profiles are derived under the assumption that the continuum emission is due entirely to the $\mathrm{NO}+\mathrm{O}$ air afterglow reaction. Vertical profiles of the atomic oxygen density, which are required to determine the nitric oxide concentrations, are derived from coordinated WINDII measurements of the atomic oxygen OI $557.7 \mathrm{~nm}$ nightglow emission. Data coverage for local solar times ranging from $20 \mathrm{~h}$ to $04 \mathrm{~h}$, and latitudes ranging from $42^{\circ} \mathrm{S}$ to $42^{\circ} \mathrm{N}$, is achieved by zonally averaging and binning data obtained on 18 nights during a two-month period extending from mid-November 1992 until mid-January 1993. The derived nitric oxide concentrations are significantly smaller than those obtained from rocket measurements of the airglow continuum but they do compare well with model expectations and nitric oxide densities measured using the resonance fluorescence technique on the Solar Mesosphere Explorer satellite. The near-global coverage of the WINDII observations and the similarities to the nitric oxide global morphology established from other satellite measurements strongly suggests that the $\mathrm{NO}+\mathrm{O}$ reaction is the major source of the continuum near $553 \mathrm{~nm}$ and that there is no compelling reason to invoke additional sources of continuum emission in this immediate spectral region.
\end{abstract}

Key words. Atmospheric composition and structure (airglow and aurora; thermosphere - composition and chemistry; instruments and techniques)

\section{Introduction}

The source of the terrestrial nightglow continuum has been a topic of active research for more than four decades. Barbier et al. (1951) were the first to find indications for the existence of a weak continuum between characteristic nightglow features and Krassowsky (1951) was the first to propose that the source of the nightglow continuum was the chemiluminescent recombination of nitric oxide and atomic oxygen. Barbier and Glaume (1960) claimed to have found evidence suggesting that the $\mathrm{NO}+\mathrm{O}$ recombination reaction could not be the only source of the nightglow continuum. They reported correlations between the oxygen OI $557.7 \mathrm{~nm}$ greenline and the nightglow continuum intensities that were inconsistent with the $\mathrm{NO}+\mathrm{O}$ source if the green line emission rate scaled as $[\mathrm{O}]^{3}$. Subsequent groundbased observations by Gadsden and Marovich (1973) and Sternberg and Ingham (1972) showed that the general similarity between the spectral distribution of the nightglow continuum and the $\mathrm{NO}+\mathrm{O}$ chemiluminescence spectrum, as measured in the laboratory, did not extend to wavelengths beyond $700 \mathrm{~nm}$. Further questions about the proposed mechanism were raised when rocket measurements of the continuum reported by Sharp (1978), Witt et al. (1981), McDade et al. (1984) and McDade et al. (1986a) were used to derive concentrations of nitric oxide based on the assumption that the $\mathrm{NO}+\mathrm{O}$ reaction was the only continuum source. These studies resulted in derived NO concentrations that were significantly larger than the NO concentrations obtained from daytime measurements of resonantly scattered sunlight in the $(1,0)$ gamma band of NO.

The rocket measurements reported by Sharp (1978) and Witt et al. (1981) were carried out at high latitude during, or immediately after, auroral disturbances and this may have caused the nitric oxide concentrations and, therefore, the nightglow continuum intensities to be elevated. However, the rocket measurements reported by McDade et al. (1984) and McDade et al. (1986a) 
were carried out under relatively quiet geomagnetic conditions, yet they still indicated very large nitric oxide concentrations. McDade et al. (1986a) therefore questioned the validity of the $\mathrm{NO}+\mathrm{O}$ mechanism and showed that it certainly could not be the only source of the airglow continuum in the red spectral region near $714 \mathrm{~nm}$.

The unrealistically high NO densities required to explain the rocket measurements of the green nightglow continuum led Bates (1993) to argue that the NO+O reaction could not be the major source of the continuum in any spectral region.

In the present work we use green nightglow continuum measurements made by the Wind Imaging Interferometer (WINDII) on the Upper Atmosphere Research Satellite (UARS) to re-examine this issue. We derive nitric oxide densities from the WINDII observations and assess how the derived densities compare with model expectations and previous satellite measurements.

\section{Measurements, data processing and analysis}

The WINDII instrument used to make the nightglow continuum measurements is described in detail by Shepherd et al. (1993). The instrument is a limb-imaging fieldwidened Michelson interferometer capable of measuring airglow emission rates and their Doppler shifts and widths in order to determine winds and temperatures in the upper mesosphere and lower thermosphere. For the present work we use WINDII observations of the emission profiles of the green nightglow continuum at $553.1 \mathrm{~nm}$ and the atomic oxygen greenline emission at $557.7 \mathrm{~nm}$.

The inclination of the UARS satellite is $57^{\circ}$ and for its nominal altitude of approximately $585 \mathrm{~km}$ the local solar time (LST) of the observation point for a particular latitude drifts by approximately 20 min per day. Therefore, 36 days of WINDII observations have to be analyzed to achieve a complete local solar time coverage of $24 \mathrm{~h}$ at each latitude. The present study uses WINDII data covering latitudes from $42^{\circ} \mathrm{S}$ to $42^{\circ} \mathrm{N}$ for local solar times ranging from $20 \mathrm{~h}$ to $04 \mathrm{~h}$. The basic aim of this investigation was to use WINDII oxygen greenline measurements to derive vertical profiles of the atomic oxygen concentration, and then combine these atomic oxygen densities with the WINDII continuum measurements in order to derive nitric oxide densities under the assumption that the $\mathrm{NO}+\mathrm{O}$ air afterglow reaction is the sole continuum source.

As part of normal operations for obtaining winds from the oxygen greenline WINDII measures both the greenline limb intensity with a filter centred at $558.4 \mathrm{~nm}$ and the background limb intensity using a filter centred at $553.1 \mathrm{~nm}$. This latter background channel, which has a passband of $1.6 \mathrm{~nm}$ (FWHM), was used to determine the nightglow continuum emission rates.

The binning procedures used for both the atomic oxygen greenline and the background continuum were identical. Since WINDII observes greenline emissions on two days and two nights each week, 18 nights of observations between November 10th, 1992 and January 9 th, 1993 had to be analyzed in order to obtain the desired latitudinal and local time coverage. Individual profiles of the greenline volume emission rates and the nightglow continuum emission rates were zonally averaged and binned into intervals of 1 hour in LST and 6 degrees in latitude.

\subsection{The nightglow continuum measurements}

In the case of the nightglow continuum measurements optical contamination arising from zodiacal light and galactic light was subtracted from the measured limb radiances prior to inversion to volume emission rates. This was achieved using the tables for the brightnesses of these extraterrestrial sources at $557.7 \mathrm{~nm}$ reported by Abreu et al. (1982). The viewing directions associated with each CCD-bin of WINDII's field-of-view were transformed into Geocentric Solar Ecliptic (GSE) and Geocentric Equatorial Inertial (GEI) coordinate systems in order to subtract the extraterrestrial contributions. Since the maps provided by Abreu et al. (1982) are partially incomplete, those WINDII measurements that fell within the Abreu et al. (1982) data gaps were rejected. The uncertainties of approximately 2 Rayleigh $/ \mathrm{nm}$ in the zodiacal and galactic light contributions lead to similar absolute uncertainties in the corrected WINDII limb radiances. For example, at a tangent height of $95 \mathrm{~km}$ a typical corrected limb radiance is approximately 20 Rayleigh $/ \mathrm{nm}$ so the uncertainty in the background leads to an uncertainty in the corrected radiance of approximately $\pm 10 \%$. At a tangent height of $110 \mathrm{~km} \mathrm{a}$ typical corrected limb radiance is about 4 Rayleigh $/ \mathrm{nm}$ so the uncertainty in the corrected limb radiance is approximately $\pm 50 \%$. As with all nightglow continuum measurements, extraterrestrial background correction is an important issue. However, in the case of WINDII's limb viewing geometry, which amplifies the airglow contribution relative to the background, background correction is much less of a problem than it is for ground-based continuum measurements as discussed by Gadsden and Marovich (1973).

As the WINDII $553 \mathrm{~nm}$ limb measurements are normally only used to correct the WINDII $558 \mathrm{~nm}$ greenline limb observations, they were not automatically inverted to volume emission profiles by the WINDII Scientific Data Production Processing Software (SDPPS) effective at the time of this study. Because of this, the inversion of the $553 \mathrm{~nm}$ continuum measurements had to be carried out off-line. For this purpose a constrained linear least squares fitting routine with statistical weighting was used and the inversion was based on the assumption that the atmosphere could be approximated by a set of 21 homogeneously emitting layers of $2 \mathrm{~km}$ thickness, ranging from $75 \mathrm{~km}$ to $117 \mathrm{~km}$. The inversion was constrained by the condition that the sum of the squared differences between the actual measurements and the reconstructed integrated emission rates was equal to the sum of the variances of the brightnesses of a single profile multiplied by $2 / 3$ : 
$\chi^{2}=\sum_{i=1}^{N}\left(\sum_{j=1}^{M} K_{i j} x_{j}-y_{i}\right)^{2}=(2 / 3) \sum_{i=1}^{N} \sigma_{y_{i}}^{2}$

where $x$ represents the solution estimate for the vertical volume emission rate profile and $y$ represents the observed integrated emission rate profile. The $K$-matrix elements, or geometric weighting functions, establish a linear relationship between $x$ and $y$ with $\sigma_{y_{i}}^{2}$ denoting the variance of the $i$-th element of $y$.

\subsection{The OI greenline measurements and the vertical atomic oxygen profiles}

The greenline data used was WINDII level 2 data, where the background contributions and dark current have been subtracted, the conversion to Rayleigh units carried out, and the integrated emission rate profiles inverted to volume emission rate profiles using the standard SDPPS software. Figure 1 shows a typical greenline emission profile obtained by averaging all of the profiles within a particular local time/latitude bin. Vertical profiles of atomic oxygen were derived from the greenline volume emission rates using the photochemical model and empirical parameters described by McDade et al. (1986b) together with the background densities and temperatures given by the MSIS 86 model (Hedin, 1987). The McDade et al. (1986b) greenline model is based on a Barth transfer mechanism and although the actual greenline excitation mechanism is not yet fully understood, this model is the one most widely used to infer oxygen atom densities from greenline volume emission rates. Since the MSIS 86 predictions for the

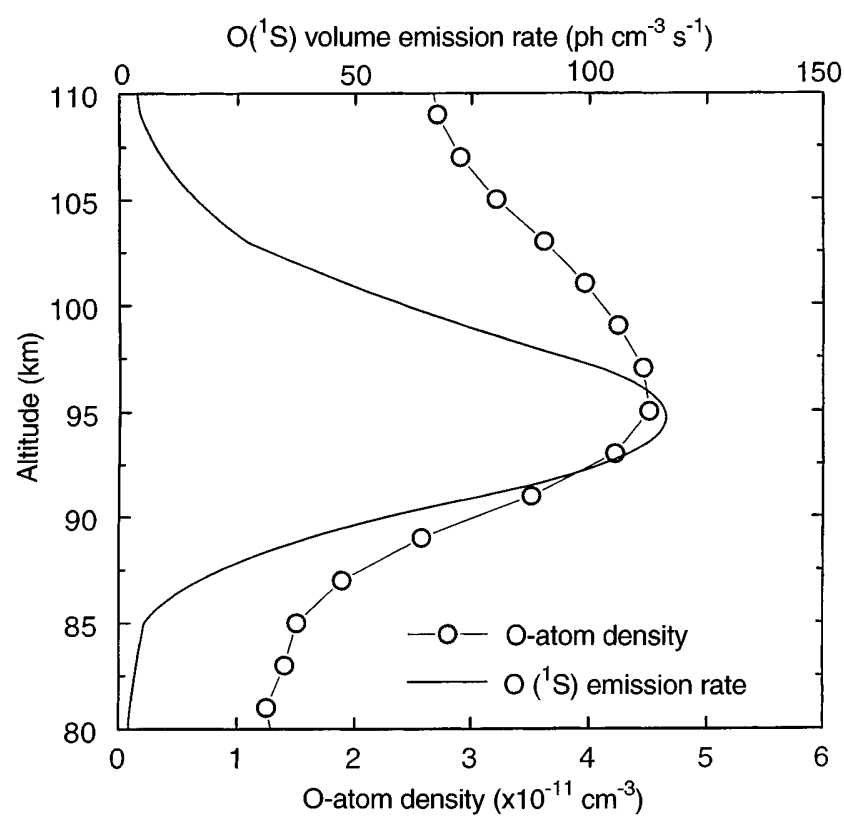

Fig. 1. A typical WINDII greenline volume emission profile (solid line) and the atomic oxygen densities derived from it as described in the text (open circles). This greenline profile was obtained by averaging all of the profiles within the local solar time/latitude bin $21-22 \mathrm{~h} / 30^{\circ} \mathrm{S}-24^{\circ} \mathrm{S}$ vertical profiles of temperature, $\left[\mathrm{N}_{2}\right]$ and $\left[\mathrm{O}_{2}\right]$ are not strongly dependent on longitude, the required profiles for each LST/latitude bin were obtained from the MSIS 86 predictions for $0^{\circ}$ longitude. Figure 1 shows an example of an atomic oxygen profile derived from the WINDII greenline emission rates.

\subsection{The nitric oxide concentrations}

In order to derive nitric oxide concentrations from the nightglow continuum measurements and the atomic oxygen profiles we have assumed that the $\mathrm{NO}+\mathrm{O}$ air afterglow reaction is solely responsible for the measured nightglow intensities. The air afterglow reaction involves a two-body path:

$\mathrm{NO}+\mathrm{O} \stackrel{k_{1}^{\lambda}}{\longrightarrow} \mathrm{NO}_{2}+\mathrm{h} v$

with a wavelength dependent effective rate coefficient $k_{1}^{\lambda}$, and a three-body path:

$\mathrm{NO}+\mathrm{O}+\mathrm{M} \stackrel{k_{2}^{\lambda, \mathrm{M}}}{\longrightarrow} \mathrm{NO}_{2}^{*}+\mathrm{h} v$

The excited $\mathrm{NO}_{2}$ molecules may experience quenching, with a wavelength dependent rate coefficient $k_{3}^{\lambda, \mathrm{M}}$, or they may emit with a spontaneous emission coefficient $k_{4}^{\lambda}$. The combined contributions of these two paths (McDade et al., 1986a) can be summarized as an effective two-body rate coefficient:

$k_{\mathrm{eff}}^{\lambda, \mathrm{M}}=k_{1}^{\lambda}\left\{1+d_{\mathrm{M}}^{\lambda}[\mathrm{M}] /\left(1+q_{\mathrm{M}}^{\lambda}[\mathrm{M}]\right)\right\}$

with $d_{\mathrm{M}}^{\lambda}=k_{2}^{\lambda, \mathrm{M}} / k_{1}^{\lambda}$ and $q_{\mathrm{M}}^{\lambda}=k_{3}^{\lambda, \mathrm{M}} / k_{4}^{\lambda}$. To obtain values for $k_{1}^{\lambda}, d_{\mathrm{M}}^{\lambda}$ and $q_{\mathrm{M}}^{\lambda}$ at $553 \mathrm{~nm}$ the laboratory mesurements of Becker et al. (1972) were used. Becker et al. (1972) measured the wavelength dependence of the effective two-body rate coefficient with $\mathrm{O}_{2}$ as the third body at eight different pressures and a constant temperature of $296 \mathrm{~K}$. In order to determine values for $d_{\mathrm{M}}^{\lambda}$ and $q_{\mathrm{M}}^{\lambda}$ at $\lambda=553 \mathrm{~nm}$, we used the method described by McDade et al. (1986a) and it was assumed that the ratios $d_{\mathrm{N}_{2}}^{\lambda}: d_{\mathrm{O}_{2}}^{\lambda}$ and $q_{\mathrm{N}_{2}}^{\lambda}: q_{\mathrm{O}_{2}}^{\lambda}$ for $\lambda=553 \mathrm{~nm}$ were the same as those for $\lambda=445 \mathrm{~nm}$ which was the wavelength studied by Becker et al. (1972). The derived coefficients are shown in Table 1.

Since the experiments reported by Becker et al. (1972) were carried out at a temperature of $296 \mathrm{~K}$, the temperature dependence of the rate coefficients has to be taken into account. For the three-body reaction path we followed the example of McDade et al. (1986a) and used the temperature dependence reported by Whytock et al. (1976), i.e. the three-body component of the effective

Table 1. The required $\mathrm{NO}+\mathrm{O}$ rate parameters for $\lambda=553 \mathrm{~nm}$

\begin{tabular}{ll}
\hline$k_{1}^{\lambda}$ & $9.9 \times 10^{-21}$ (photons $\left./ \mathrm{nm}\right) \mathrm{cm}^{3} \mathrm{molec}^{-2} \mathrm{~s}^{-1}$ \\
$d_{\mathrm{O}_{2}}^{\lambda}$ & $2.57 \times 10^{-14} \mathrm{~cm}^{3} \mathrm{molec}^{-2} \mathrm{~s}^{-1}$ \\
$q_{\mathrm{O}_{2}}^{\lambda}$ & $2.50 \times 10^{-15} \mathrm{~cm}^{3} \mathrm{molec}^{-2} \mathrm{~s}^{-1}$ \\
$d_{\mathrm{N}_{2}}^{\lambda}$ & $3.16 \times 10^{-14} \mathrm{~cm}^{3} \mathrm{molec}^{-2} \mathrm{~s}^{-1}$ \\
$q_{\mathrm{N}_{2}}^{\lambda}$ & $2.80 \times 10^{-15} \mathrm{~cm}^{3} \mathrm{molec}^{-2} \mathrm{~s}^{-1}$ \\
\hline
\end{tabular}


two-body rate coefficient was adjusted for atmospheric temperature using a temperature correction factor given by $\mathrm{F}(T)=\exp (584 \times(1 / T-1 / 296))$.

For the temperature dependence of the two-body component two approaches, identified as case $\mathrm{A}$ and case $\mathrm{B}$, were used. In case $\mathrm{A}$ it was assumed that the two-body reaction, reaction 2 , had no temperature dependence. In the second case, case B, it was assumed that the two-body component had a temperature dependence as proposed by Sharp (1984), who suggested an Arrhenius temperature dependence with a positive

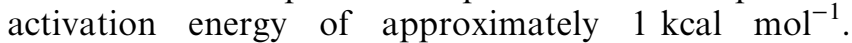
Since the continuum emission rates are simply related to the oxygen atom densities and nitric oxide densities by $\mathrm{V}^{\lambda}=k_{\text {eff }}^{\lambda, \mathrm{M}}[\mathrm{O}][\mathrm{NO}]$, the nitric oxide densities can be readily inferred from the measured continuum emission rates and the local atomic oxygen densities. Figure 2 shows a typical $553 \mathrm{~nm}$ nightglow continuum profile measured by WINDII for the local solar time/ latitude bin $21-22 \mathrm{hr} / 30^{\circ} \mathrm{S}-24^{\circ} \mathrm{S}$ and Figure 3 shows the nitric oxide concentrations derived for this local solar time/latitude bin using the case A and case B effective two-body rate coefficients. Note that the major source of uncertainty in the derived continuum emission rates originates from the extraterrestrial background correction discussed in Sect. 2.1 and this is reflected by the error bars in Fig. 2. This propagates through to the derived nitric oxide concentrations as shown in Fig. 3 which are also subject to any systematic errors in the atomic oxygen densities derived from the greenline observations using the McDade et al. (1986b) model.

Examples of how the atomic oxygen and derived nitric oxide densities vary with altitude and local time for one of the latitude bins are shown in Figs. 4, 5 and 6. Figure 4 shows an atomic oxygen concentration contour plot for latitudes between $30^{\circ} \mathrm{S}$ and $24^{\circ} \mathrm{S}$ as a function of

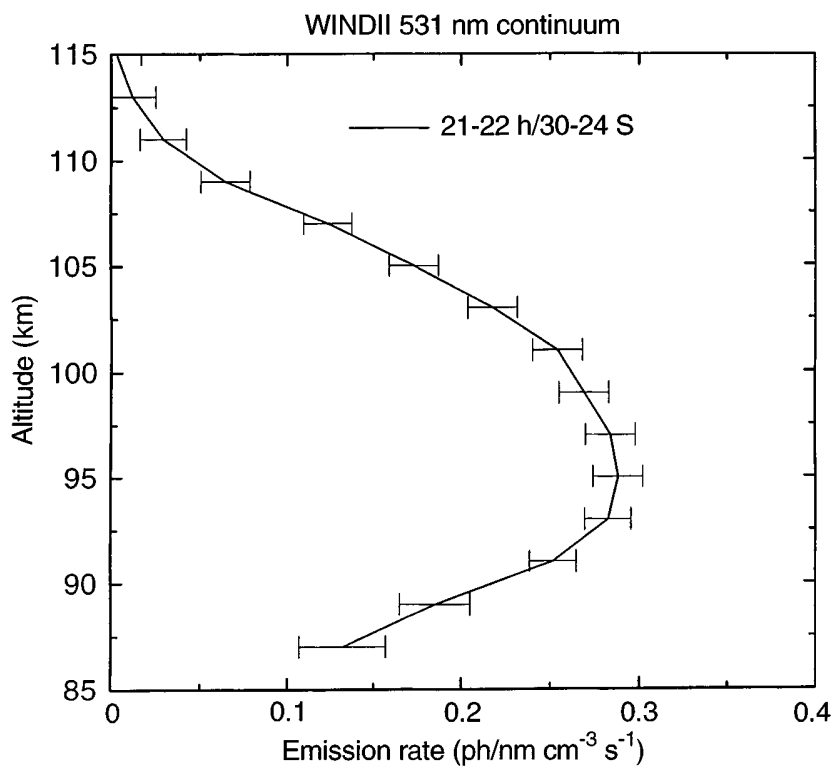

Fig. 2. The $553 \mathrm{~nm}$ nightglow continuum volume emission rates measured by WINDII for the same local solar time/latitude bin as Fig. 1

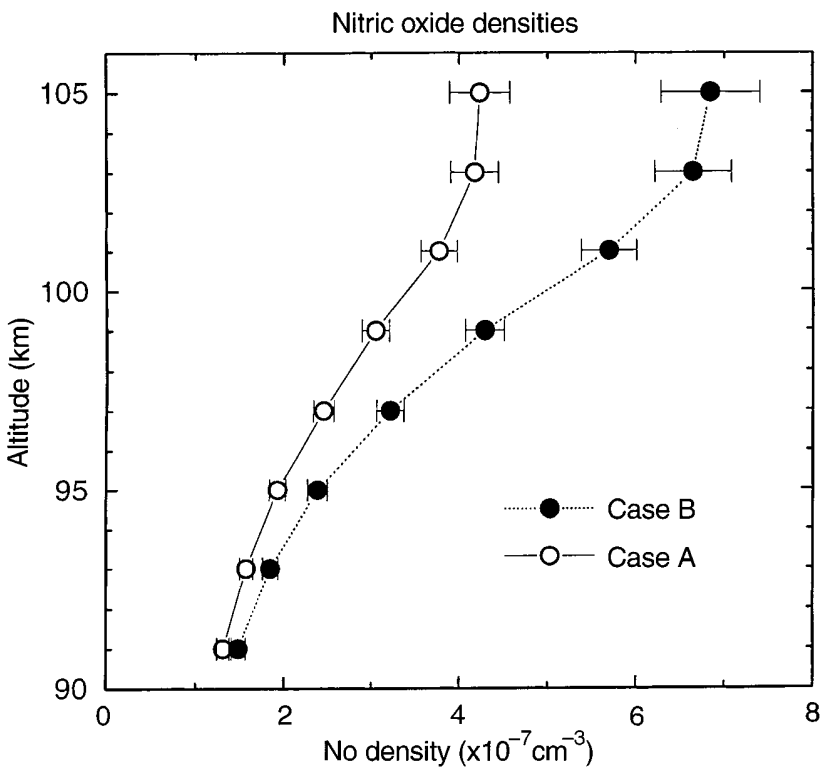

Fig. 3. The nitric oxide densities derived from the continuum emission rates of Fig. 2 and the atomic oxygen densities of Fig. 1. The solid line shows the densities obtained with the case $\mathrm{A}$ rate coefficients and the dashed line shows the densities obtained for case B

local solar time and altitude. The concentrations clearly show the influence of tidal effects, but a detailed discussion of these tidal signatures is beyond the scope of this work. For a discussion of these effects see McLandress et al. (1996). Figures 5 and 6 show contour plots of the nitric oxide concentrations derived using the Fig. 4 atomic oxygen concentrations. The mean derived nitric oxide concentration at $105 \mathrm{~km}$ is approximately $3.7 \times 10^{7}$ molecule $\mathrm{cm}^{-3}$ for case $\mathrm{A}$ and $6.3 \times 10^{7}$ molecule $\mathrm{cm}^{-3}$ for case $\mathrm{B}$, averaged over the LST range covered. Near the equator the derived nitric oxide densities for adjacent LST/latitude bins show larger variations than those between $30^{\circ} \mathrm{S}$ and $24^{\circ} \mathrm{S}$. The mean

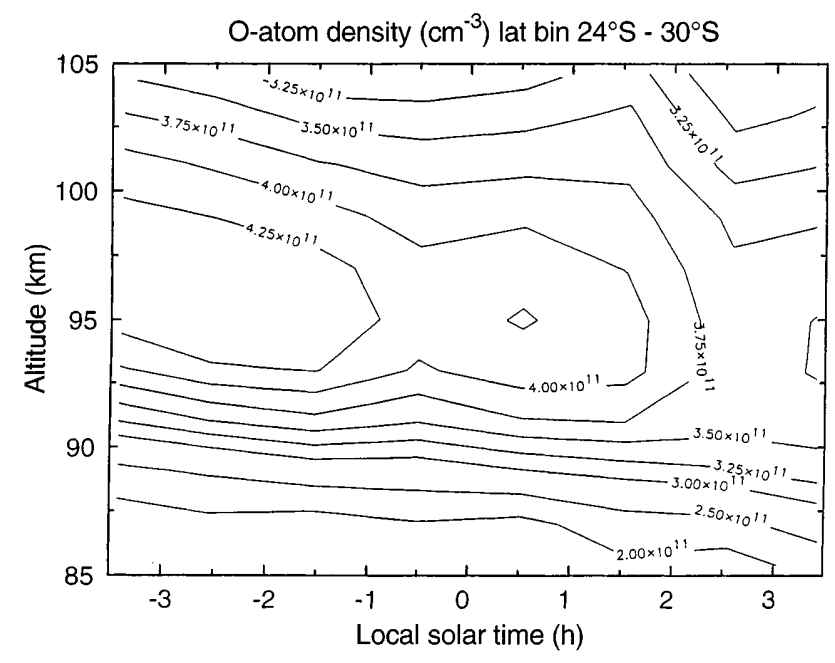

Fig. 4. A contour plot of the atomic oxygen densities derived from the WINDII greenline measurements for the latitude bin $30^{\circ} \mathrm{S}$ to $24^{\circ} \mathrm{S}$ as a function of local solar time and altitude 


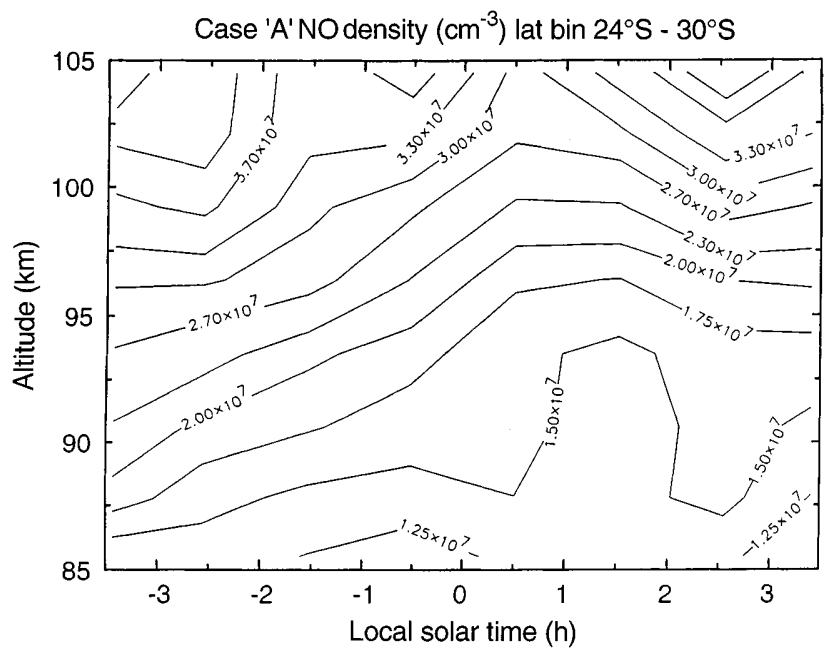

Fig. 5. A contour plot of the nitric oxide densities derived from the WINDII continuum measurements using the case A coefficients for the latitude bin $30^{\circ} \mathrm{S}$ to $24^{\circ} \mathrm{S}$ as a function of local solar time and altitude

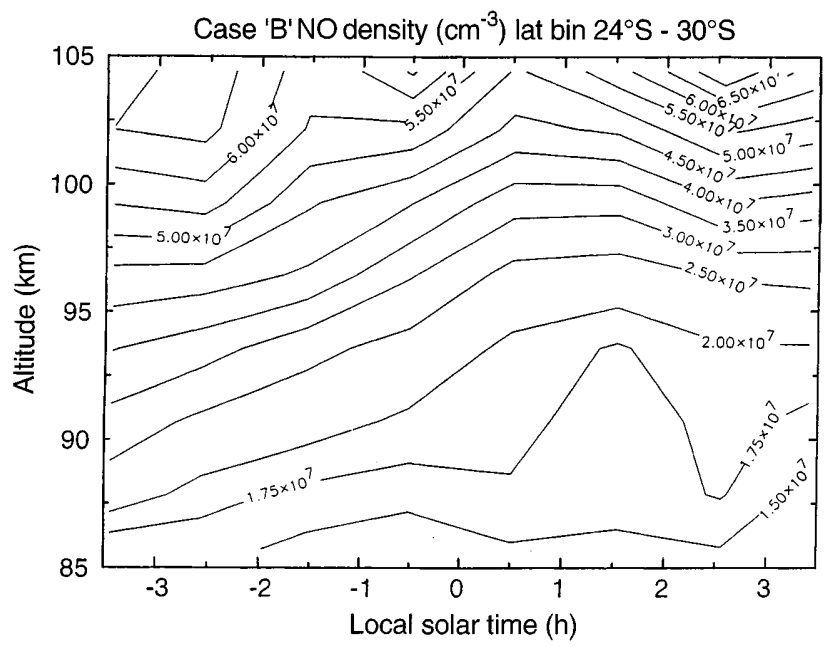

Fig. 6. A contour plot of the nitric oxide densities derived from the WINDII continuum measurements using the case B coefficients for the latitude bin $30^{\circ} \mathrm{S}$ to $24^{\circ} \mathrm{S}$ as a function of local solar time and altitude

nitric oxide density between $6^{\circ} \mathrm{S}$ and $6^{\circ} \mathrm{N}$, at an altitude of $105 \mathrm{~km}$ and averaged over local solar times from $20 \mathrm{~h}$ to $04 \mathrm{~h}$ is about $1.75 \times 10^{7}$ molecule $\mathrm{cm}^{-3}$ for case $\mathrm{A}$ and approximately $3.2 \times 10^{7}$ molecule $\mathrm{cm}^{-3}$ for case $\mathrm{B}$.

\section{Discussion}

As already mentioned, rocket measurements of the nightglow continuum in the green spectral region (Sharp, 1978; Witt et al., 1981; McDade et al., 1984; McDade et al., 1986a) have previously been used to deduce profiles of nitric oxide densities. Since the nitric oxide concentrations obtained from these rocket studies were significantly larger than what would be expected for airglow altitudes, the hypothesis that the $\mathrm{NO}+\mathrm{O}$ air afterglow reaction is the principal source of the night- glow continuum has been called into serious question (McDade et al., 1986a; Bates, 1993).

An important result of the present analysis is that the nitric oxide densities derived from the WINDII continuum measurements are about an order of magnitude smaller than those obtained from the rocket experiments and they compare much more favourably with model expectations and other satellite-based nitric oxide measurements.

Nitric oxide densities have been measured by the Ultraviolet Nitric Oxide Experiments (UVNO) on the Atmosphere Explorer ' $C$ ' and ' $D$ ' satellites (Cravens and Stewart, 1978) and by the Solar Mesospheric Explorer (SME) satellite (Barth, 1992). Although the UVNO and SME experiments provided only daytime nitric oxide densities it is still meaningful to compare the UVNO and SME densities with the present WINDII nighttime densities since time dependent models do not predict strong diurnal variations at the altitudes of interest (Ogawa and Kondo, 1977) and the analysis of Stewart and Cravens (1978) has shown that the diurnal variations in the nitric oxide densities below $110 \mathrm{~km}$ should not be greater than a factor of about 2 .

The SME nitric oxide densities reported by Barth (1992) compare very favourably with the WINDII nitric oxide densities especially when the solar cycle effects are taken into account. Barth (1992) presents continuous nitric oxide observations between 1982 when solar activity was very high and 1986 when the solar minimum was reached. The daily average $110 \mathrm{~km}$ nitric oxide concentrations between $30^{\circ} \mathrm{S}$ and $30^{\circ} \mathrm{N}$ were reported to vary from $1.6 \times 10^{7}$ molecule $\mathrm{cm}^{-3}$ to $3.3 \times 10^{7}$ molecule $\mathrm{cm}^{-3}$ during the last two months of 1982 when the level of solar activity was similar to that experienced at the time of the WINDII observations. These SME densities compare quite favourably with the case A WINDII densities presented but it should be noted that the analysis of the SME observations did not take optical depth effects into account and the reported SME densities could be underestimated by up to a factor of 2 (Barth, 1992).

In the case of the Atmosphere Explorer ' $\mathrm{C}$ ' UVNO experiment, Stewart and Cravens (1978) reported zonally averaged peak nitric oxide concentrations of $2.5 \times 10^{7}$ molecule $\mathrm{cm}^{-3}$ for northern winter conditions at latitudes slightly equatorwards of $30^{\circ}$. Cravens et al. (1985) presented NO observations made on the Atmosphere Explorer ' $D$ ' satellite during the winter of 1975 1976 and reported maximum NO concentrations of approximately $1 \times 10^{7}$ molecule $\mathrm{cm}^{-3}$ at latitudes around $30^{\circ} \mathrm{S}$. All of the reported UVNO peak concentrations at latitudes within the interval $0-30^{\circ} \mathrm{S}$ have values below $2.5 \times 10^{7}$ molecule $\mathrm{cm}^{-3}$ and they are therefore somewhat smaller than the densities derived here from the WINDII observations. The differences between the WINDII and UVNO nitric oxide densities are about a factor 2 for the case A scenario and a factor of 4 for the case B scenario. However, it is important to note that the AE-C and AE-D measurements were made close to the end of solar cycle 20 when the level of solar activity was significantly lower than at the time of the presently analyzed WINDII observations. 
Perhaps what is more significant in the case of the WINDII versus UVNO comparison is the similarity between the latitudinal dependence of the UVNO and WINDII nitric oxide distributions. Figure 7 shows the latitudinal dependence of the nitric oxide densities derived in this work for an altitude of $100 \mathrm{~km}$. These densities were obtained by averaging the nitric oxide profiles for each latitude bin over all available local solar times. As the shapes of the plots are very similar for both case A and case B we only present in Fig. 7 the case B plot. For case A the densities are slightly lower with a Southern Hemisphere (summer) maximum of about $3.2 \times 10^{7}$ molecule $\mathrm{cm}^{-3}$ at latitudes between $42^{\circ} \mathrm{S}$ and $36^{\circ} \mathrm{S}$, and a Northern Hemispheric (winter) maximum of about $2.5 \times 10^{7}$ molecule $\mathrm{cm}^{-3}$ at latitudes between $36^{\circ} \mathrm{N}$ and $42^{\circ} \mathrm{N}$. The average equatorial nitric oxide density is $2.0 \times 10^{7}$ molecule $\mathrm{cm}^{-3}$. Figure 7 shows two important features. First, there is more nitric oxide at higher latitudes, which is quite consistent with what is currently known about nitric oxide global morphology. Second, there is a greater abundance of nitric oxide in the summer (southern) hemisphere, which was also observed by Cravens and Stewart (1978). Figure 7 should be compared to Fig. 5a of Cravens and Stewart (1978). The latter figure shows the latitudinal dependence of the UVNO zonally averaged instrument counts and an estimate of the associated nitric oxide densities. The densities decrease almost linearly between $30^{\circ} \mathrm{S}$ and $30^{\circ} \mathrm{N}$ with a discernible increase towards higher latitudes in the Northern Hemisphere. Cravens and Stewart (1978) also found that the best linear fit through their dataset led to approximate nitric oxide concentrations of $2.8 \times 10^{7}$ molecule $\mathrm{cm}^{-3}$ at $30^{\circ} \mathrm{S}$ and $2.3 \times 10^{7}$ molecule $\mathrm{cm}^{-3}$ at the equator. The data used for Fig. $5 \mathrm{a}$ of Cravens and Stewart were all obtained using northern winter measurements made on days 334-045 of 1974 when the $A p$ index was less than $40-$ a condition that is

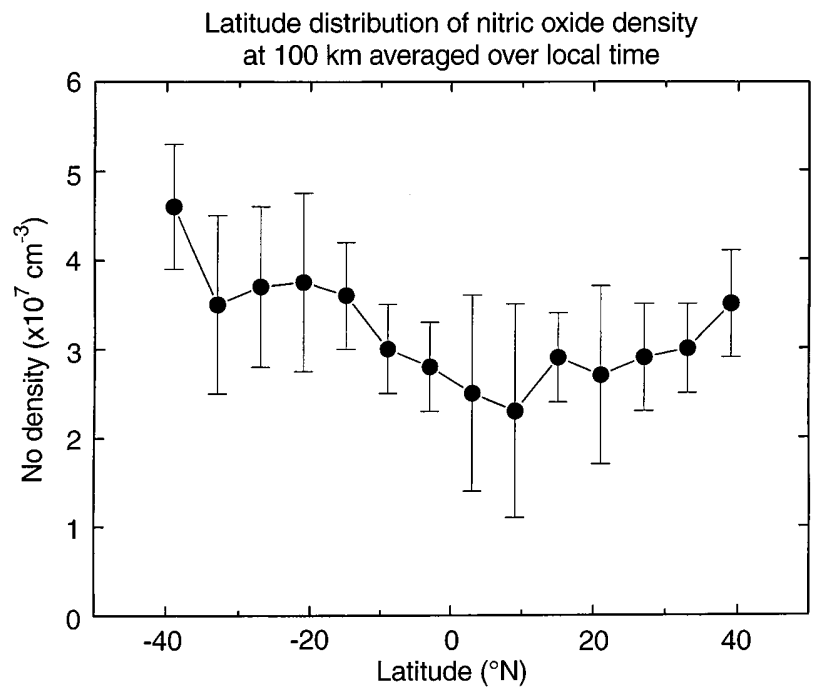

Fig. 7. The northern winter latitudinal dependence of the case $B$ nitric oxide concentrations at $100 \mathrm{~km}$ obtained by averaging the profiles for all available local solar times. The error bars show the standard deviation of the densities used to obtain the average also approximately satisfied by the present WINDII dataset. There were only two days during the 2-month period of the WINDII observations when the $A p$ index was larger than 40. The similarities between Fig. 5a of Cravens and Stewart (1978) and the present Fig. 7 are very striking and clearly the global morphology of the nitric oxide densities derived from the WINDII nightglow continuum measurements is very similar to the nitric oxide morphology established by the Atmosphere Explorer UVNO experiments.

It seems, therefore, that the WINDII limb observations of the green nightglow continuum are quite consistent with the $\mathrm{NO}+\mathrm{O}$ air afterglow reaction being the major source of the continuum at $553 \mathrm{~nm}$. This appears to contradict the results of the rocket experiments which measured much stronger continuum emission rates and derived much larger nitric oxide densities. As already mentioned, in the case of the rocket experiments of Sharp (1978) and Witt et al. (1981) this might be explained by auroral enhancement of the nitric oxide densities but auroral enhancement can not explain the McDade et al. (1984) and McDade et al. (1986a) observations.

The continuum volume emission rates reported by McDade et al. (1984) and McDade et al. (1986a) are about an order of magnitude larger than those derived from the present WINDII limb observations. The green continuum rocket measurements of McDade et al. (1984) and McDade et al. (1986a) were obtained using filter photometers centred on $532 \mathrm{~nm}$ and $540 \mathrm{~nm}$, with passbands of $11 \mathrm{~nm}$ and $12 \mathrm{~nm}$ respectively; whereas the WINDII observations were made with a filter centred on $553.1 \mathrm{~nm}$ with a passband of only $1.6 \mathrm{~nm}$. In the case of the WINDII measurements the only 'known' contaminant is the $\mathrm{OH}$ Meinel (7-1) band which has a nominal zenith airglow intensity of $\sim 10$ Rayleighs (Llewellyn et al., 1978). The WINDII $553 \mathrm{~nm}$ filter captures less than $1 \%$ of this band so the $\mathrm{OH}$ Meinel (7-1) band contribution is insignificant except, possibly, at the very lowest tangent heights, i.e., below $\sim 90 \mathrm{~km}$. In the case of the McDade et al. (1984) and McDade et al. (1986a) rocket experiments the major 'known' contaminant was the $\mathrm{OH}$ Meinel (6-0) band which would have been captured with efficiencies of $\sim 72 \%$ and $\sim 20 \%$ respectively. Since this band has a nominal zenith intensity of only about 3 Rayleighs (Llewellyn et al., 1978), OH (6-0) band contamination can not account for the anomalously high continuum emission rates measured in these rocket experiments. Clearly, the discrepancy between the present WINDII nightglow continuum measurements and the previous rocket measurements can not be explained by interference from known airglow sources. We suggest, therefore, that the narrow passband WINDII instrument captured primarily the $\mathrm{NO}+\mathrm{O}$ continuum emission and that the wider filters on the rocket photometers captured, in addition, some other unidentified weak nightglow features. As McDade et al. (1986a) have pointed out, some other weak source of emission must have contributed to their simultaneous red continuum measurement at $714 \mathrm{~nm}$ and they speculated that it might be the (4-3) band of the $\mathrm{O}_{2}$ 
atmospheric system. This hypothesis has recently been confirmed by Osterbrock et al. (1996) who have now identified the $\mathrm{O}_{2}$ atmospheric (4-3) band emission in ground-based nightglow spectra obtained with the Keck telescope.

It is also possible that the McDade et al. (1984) and McDade et al. (1986a) rocket measurements may have been contaminated by vehicle-induced emission, or 'rocket glow'. Vehicle-induced emission is a spurious feature of rocket photometry measurements particularly those of weak airglow features. As explained by McDade et al. (1987), vehicle-induced emission can be unambiguously identified by a transient increase in the zenith airglow intensity measured by a rocket photometer as it penetrates an airglow layer. Although transient increases in signal were not observed in these rocket experiments, vehicle-induced emissions can go unidentified on the upleg of a rocket flight if the natural ambient nightglow zenith intensity decreases more rapidly than the rate at which the transient vehicleinduced emission grows. It can also go unidentified if the transient has switched on before the first photometer data are acquired and this may have occurred in these rocket experiments.

\section{Conclusion}

WINDII observations of the nightglow continuum at $533.1 \mathrm{~nm}$ have been used to deduce nitric oxide concentrations under the assumption that the continu$\mathrm{um}$ arises solely from the $\mathrm{NO}+\mathrm{O}$ air afterglow reaction. The continuum volume emission rates derived from these WINDII limb observations are substantially smaller than those previously determined from in situ rocket experiments. The nitric oxide concentrations derived from the WINDII observations compare favourably with nitric oxide densities obtained from other satellite experiments and the latitudinal gradient of the deduced densities is consistent with what is known about lower thermospheric nitric oxide morphology. The nitric oxide cocentrations have been derived for two cases which differ in the assumptions made about the temperature dependence of the two-body $\mathrm{NO}+\mathrm{O}$ recombination reaction. Since the nitric oxide concentrations derived for these two cases are substantially different there is a clear need for laboratory measurements of the temperature dependence of this important reaction. The results of the analysis suggest that, at the wavelengths observed by WINDII, the nightglow continuum can be adequately explained by the $\mathrm{NO}+\mathrm{O}$ reaction and there is no compelling reason to invoke additional sources of nightglow emission at $553 \pm 1 \mathrm{~nm}$. We are presently investigating the seasonal, longitudinal and local time variations in the nitric oxide densities derived from the WINDII continuum measurements and the results of that work will be the subject of a subsequent publication.

Acknowledgements. The authors are grateful to all members of the WINDII team, especially to Brian Solheim, whose efforts have made this study possible. C. von S. would like to thank the
Ontario/Baden-Württemberg Student Exchange Program which allowed him to join the Graduate Programme in Physics and Astronomy at York University. The WINDII project is jointly supported by the Canadian Space Agency and the Centre National d'Etudes Spatiales, France, and support for the scientific analysis of the WINDII data is provided by the Natural Sciences and Engineering Research Council of Canada.

Topical Editor F. Vial thanks T.G. Slanger and another referee for their help in evaluating this paper.

\section{References}

Abreu, V. J., J. H. Yee, and P. B. Hays, Galactic and zodiacal light surface brightness measurements with the Atmosphere Explorer Satellites, Appl. Optics, 21, 2287-2290, 1982.

Barbier, D., J. Dufay, and D. Williams, Researches sur l'émission de la raie verte de la lumière du ceil nocturne, Ann. Astrophys., 14, 399-437, 1951.

Barbier, D., and J. Glaume, Correlations entre les intensites de diverses radiations de la luminescence atmospherique nocturne, Annales Geophysicae, 16, 56-76, 1960.

Barth, C. A., Nitric oxide in the lower thermosphere, Planet. Space Sci., 40, 315-336, 1992.

Bates, D. R., Cause of terrestrial nightglow continuum, Proc. R. Soc. London, A 443, 227-237, 1993.

Becker, K.H., W. Groth, and D. Thran, The mechanism of the air afterglow $\mathrm{NO}+\mathrm{O} \rightarrow \mathrm{NO}_{2}+\mathrm{h} v$, Chem. Phys. Lett., 15, 215220, 1972.

Cravens, T. E., and A. I. Stewart, Global morphology of nitric oxide in the lower E region, J. Geophys. Res., 83, 2446-2452, 1978.

Cravens, T. E., J.-C. Gérard, M. LeCompte, A. I. Stewart, and D. W.Rusch, The global distribution of nitric oxide in the thermosphere as determined by the Atmosphere Explorer D satellite, J. Geophys. Res., 85, 9862-9870, 1985.

Gadsden, M. and E. Marovich, The nightglow continuum, J. Atmos. Terr. Phys., 53, 1601-1614, 1973.

Hedin, A. E., MSIS-86 Thermospheric model, J. Geophys. Res., 92, 4649-4662, 1987.

Krassovsky, V. I., Influence of water vapour, carbon oxides and nitrogen on the luminescence of the night sky, Dokl. Akad. Nauk. S.S.S.R., 78, 669, 1951.

Llewellyn, E. J., B. H. Long, and B. H. Solheim, The quenching of $\mathrm{OH}^{*}$ in the atmosphere, Planet. Space Sci., 26, 525-531, 1978.

McDade, I. C., G. H. Greer, and D. P. Murtagh, Thermospheric nitric oxide concentrations derived from a measurement of the altitude profile of the green nightglow continuum, Annales Geophysicae, 2, 487-493, 1984.

McDade, I. C., E. J. Llewellyn, R. G. H. Greer, and D. P. Murtagh, ETON 3: altitude profiles of the nightglow continuum at green and near infrared wavelengths, Planet. Space Sci., 34, 801-810, 1986a.

McDade, I. C., D. P. Murtagh, R. G. H. Greer, P. H. G. Dickinson, G. Witt, J. Stegman, E. J. Llewellyn, L. Thomas, and D.B. Jenkins, ETON 2: quenching parameters for the precursors of $\mathrm{O}_{2}\left(\mathrm{~b}^{1} \Sigma_{\mathrm{g}}^{+}\right)$and $\mathrm{O}\left({ }^{1} \mathrm{~S}\right)$ in the terrestrial nightglow, Planet. Space Sci., 34, 789-800, 1986b.

McDade, I. C., E. J. Llewellyn, R. G. H. Greer, and D. P. Murtagh, ETON 6: a rocket measurement of the $\mathrm{O}_{2}$ infrared atmospheric (0-0) band in the nightglow, Planet. Space Sci. 35, 1541-1552, 1987.

McLandress, C., G. G. Shepherd, and B. H. Solheim, Satellite observations of thermospheric tides: results from the Wind Imaging Interferometer on UARS, J. Geophys. Res., 101, 40934114, 1996.

Ogawa, T., and Y. Kondo, Diurnal variability of thermospheric N and NO, Planet. Space Sci., 25, 735-742, 1977.

Osterbrock, D.E., J. P. Fulbright, A. R. Martel, M. K. Keane, S. C. Trager, and G. Barsi, Night-sky high resolution spectral atlas of $\mathrm{OH}$ and $\mathrm{O}_{2}$ emission lines for echelle spectrograph wavelength calibration, Pub. Astron. Soc. Pac., 108, 277-308, 1996. 
Sharp, W. E. NO continuum in the aurora, J. Geophys. Res., 83, 4373-4376, 1978.

Sharp, W. E. On the temperature dependence of the reaction $\mathrm{NO}+\mathrm{O} \rightarrow \mathrm{NO}_{2}^{*}$, Planet. Space Sci., 32, 257, 1984.

Shepherd, G. G. et al., WINDII: the wind imaging interferometer on the upper atmosphere research satellite, J. Geophys. Res., 98, $10725-10750,1993$.

Sternberg, J.R., and M. F. Ingham, Observations of the airglow continuum, Mon. Not. R. Astron Soc., 159, 1-10, 1972.
Stewart, A. I., and T. E. Cravens, Diurnal and seasonal effects in E region low-latitude nitric oxide, J. Geophys. Res., 83, 24532456, 1978.

Whytock, D.A., J. V. Michael, and W. A. Payne, Absolute rate constants for $\mathrm{NO}+\mathrm{O}+\mathrm{N}_{2} \rightarrow \mathrm{NO}_{2}+\mathrm{N}_{2}$ from 217-500 K, Chem. Phys. Lett., 42, 466-471, 1976.

Witt, G., J. Rose, and E. J. Llewellyn, The airglow continuum at high latitudes - an estimate of the NO concentration, J. Geophys. Res., 86, 623-628, 1981. 